\title{
PROPRIEDADES MEDICINAIS DE PLANTAS DO MANGUE DO ESTADO DE PERNAMBUCO
}

\section{MEDICINAL PROPERTIES OF MANGROVE PLANTS OF THE STATE OF PERNAMBUCO}

\author{
Ricardo Sérgio da Silva ${ }^{1}$; Zion Nascimento de Souza ${ }^{2}$; Rayza Helen Graciano dos Santos ${ }^{3}$; Elielma Josefa de \\ Moura $^{4}$; Isabelly Fernanda Santos Barbosa ${ }^{5}$
}

DOI: $\underline{\text { https://doi.org/10.31692/978-65-991061-9-4.44-55 }}$

\section{RESUMO}

O Estado de Pernambuco se situa na região Nordeste do Brasil e tem aproximadamente 98.311 $\mathrm{km}^{2}$ de extensão. Além disso, sua vasta biodiversidade é uma das suas principais características, e, dentre seus ecossistemas destaca-se o manguezal, que é um ecossistema costeiro de transição entre os biomas terrestre e marinho. Baseado nisso, o presente estudo tem como objetivo a observação e discussão a respeito das propriedades medicinais de plantas do mangue Pernambucano. Para isso, foi realizado um levantamento qualitativo a respeito das características e propriedades das plantas do manguezal. Tal levantamento foi realizado por meio da análise de 25 artigos das plataformas Scielo e Google Acadêmico, datados entre 2008 e 2019. Por meio destes, foi possível constatar a importância e utilidade das plantas provenientes do mangue do Estado de Pernambuco para a comunidade e para fins farmacêuticos. Como resultados, foram identificadas 4 espécies de plantas pertencentes a 3 famílias e seu caráter medicinal no uso pela população e indústria.

Palavras-chave: Mangue; Pernambuco; Plantas Medicinais; Uso Medicinal.

\section{ABSTRACT}

The state of Pernambuco is located in the northeast region of Brazil and is approximately 98,311 $\mathrm{km}^{2}$ in length. In addition, its vast biodiversity is one of its main characteristics, and among its ecosystems stands out the mangrove, which is a coastal ecosystem of transition between the terrestrial and marine bioms. Based on this, the present study aims to observe and discuss the medicinal properties of mangrove plants in Pernambuco. For this, a qualitative survey was carried out regarding the characteristics and properties of the mangrove plants. This research was carried out through the analysis of 25 articles from Scielo and Google scholar platforms, dated between 2008 and 2019. Through these, it was possible to verify the importance and usefulness of the plants from the mangrove of the state of Pernambuco to the community and for pharmaceutical purposes. As results, 4 species of plants belonging to 3 families and their medicinal nature in the use by the population and industry were identified.

Keywords: Mangrove; Medicinal plants; Medicinal use; Pernambuco.

\section{INTRODUÇÃO}

O manguezal é um ecossistema costeiro, característico de regiões tropicais e subtropicais, situado na interface entre os ambientes terrestres e marinhos. Sujeito ao regime

\footnotetext{
${ }^{1}$ Mestre em Morfotecnologia, UFPE, profricardosergio.bio@gmail.com

${ }^{2}$ Bacharelado em Biomedicina, UFPE, zionnascimento@ hotmail.com

${ }^{3}$ Mestra em Morfotecnologia, UFPE, isabelly_barbosa@ hotmail.com

${ }^{4}$ Bacharelado em Agronomia, IFPE, elielmamoura@outlook.com

${ }^{5}$ Graduada em Ciências Biológicas, UFPE, rayzahelen@ hotmail.com
} 
das marés apresenta sedimentos predominantemente lodosos, com baixos teores de oxigênio dissolvido. A vegetação é uma floresta inundada constituída por espécies lenhosas típicas (Schaeffer-Novelli, 1995).

Os manguezais do Brasil, apresentam uma vasta extensão em toda a região litorânea, disponibilizando uma enorme riqueza de recursos naturais, que são explorados e utilizados por comunidades em geral desde tempos remotos (MATTOS et al., 2012). Esse ecossistema ocupa uma parcela bastante significativa do litoral brasileiro, que se estende desde o extremo norte do Amapá, até o estado de Santa Catarina, apresentando um desenvolvimento mais pleno em regiões mais próximas à linha do Equador (MATTOS et al, 2012).

No litoral brasileiro, os manguezais são caracterizados por diversas formas, extensões e características ambientais. O ambiente de mangue pode ser encontrado desde o litoral de Laguna, no Estado de Santa Catarina (região sul do país), ao Cabo Orange - no Estado do Amapá (região norte brasileira) - ocupando uma área de aproximadamente 14 mil km², o que configura o Brasil como o segundo maior detentor de áreas de manguezais no mundo (LACERDA, 2002).

Dentro da variabilidade de solos dos manguezais existem algumas características que são inerentes, como o alto teor de sais provenientes da água do mar, o hidromorfismo, o fato de que geralmente não há diferenciação de horizontes, além de uma elevada presença de matéria orgânica e cor acinzentada, proveniente do processo de gleização (MARQUES, 2010). Com o intuito de diferenciar e agrupar essas classes de solos utilizando o Sistema Brasileiro de Classificação de Solos (EMBRAPA, 2013), pode-se enquadrar os solos desses ambientes conforme seus atributos morfológicos, químicos e físicos, dentro de uma seção de controle do perfil pedológico, como: Gleissolos Tiomórficos (MARQUES, 2010) ou Organossolos Tiomórficos (FERREIRA, 2002), que apresentam pH menor que 3,5 após oxidado, tendo como produto o ácido sulfúrico, altamente tóxico para as plantas e animais. Outro aspecto importante na formação dos manguezais é a variação do nível médio do mar. Por ser um processo gradual e lento, durante essa variação ocorre uma reorganização constante no espaço desses ambientes. Sendo assim, o desenvolvimento de espaços novos pela fixação das espécies dos mangues é mais acelerado do que o processo de formação de solos. Deste modo, a cada redução ou elevação do nível médio do mar há uma adaptação dos manguezais evitando, portanto, a extinção do ecossistema (ALVES, 2001).

Sua estrutura possibilita a manutenção de diversos habitats propícios à proteção contra predadores, reprodução, desova e crescimento de diversas espécies marinhas ou de água doce. Permite também o abrigo de numerosas espécies terrestres na vegetação (Delabie et al., 2006). 
Em contrapartida, manguezais são favoráveis à instalação de portos e à fundação e expansão de cidades, sofrendo, como consequência, desmatamento, aterramento, eutrofização, entrada de elementos estranhos no sistema (poluição química e orgânica, invasão por espécies exóticas) e impactos de outras naturezas (Macintosh \& Ashton, 2005). Os impactos antrópicos podem causar alterações nas propriedades físicas, químicas e biológicas do ecossistema, refletindo-se diretamente nas relações socioeconômicas da população dependente desse meio.

As atividades tais como o desmatamento em larga escala, poluição por metais pesados provenientes de indústrias, petróleo e seus derivados, pesticidas e herbicidas, que vêm sendo desenvolvidas de forma constante e desenfreada no entorno de manguezais, atualmente e durante um longo período de tempo passado, trazem grandes impactos para o ecossistema por interferirem de forma direta ou indireta no desenvolvimento e regeneração das espécies do mangue (TEIXEIRA, 2008).

O desmatamento em áreas de manguezais é uma das alterações ambientais mais antigas no Brasil, praticado desde o século XVI. Naquela época, o corte de árvores era provocado para obtenção de tinta (tanino) utilizada para tingir tecidos e em curtumes (VANNUCCI, 2002).

O corte da vegetação de mangue além de destruir a flora, expõe o solo ao sol, provocando a evaporação mais rápida da água e, consequentemente, a salinização do substrato, resultando na morte do próprio mangue restante bem como de caranguejos e mariscos, o que afeta a produtividade e a pesca de caranguejos, camarões e peixes (ALVES, 2001).

O interesse por estudos em áreas de mangue vem sendo bastante difundido na comunidade acadêmica em decorrência de fatores como mudanças ambientais que afetam as propriedades físicas, químicas e biológicas do meio ambiente, com isso, é de grande importância a manutenção do equilíbrio ecológico no ecossistema do manguezal, bem como, a preservação da sua vasta biodiversidade (TEIXEIRA, 2008).

De acordo com estudos de Oliveira (2005) e Soares (2017), os estuários são ambientes de transição entre o continente e o oceano, onde há o encontro do rio com o mar. As espécies presentes no mangue, são plantas caracterizadas como halófitas, próprias de ambientes salinos. Esse tipo de ecossistema se destaca como sendo bastante importante para um ambiente equilibrado, pois funcionam como exportadores de matéria orgânica para os estuários, área de abrigo e reprodução para diversas espécies, além da diversidade da flora presente no local (BARBOSA, 2010).

Os manguezais têm sua importância relacionada às suas funções fundamentais, como a manutenção da qualidade da água, fixação do sedimento, fornecimento de produção primária para o entorno e manutenção da biodiversidade (KRUG et al., 2007). 


\section{FUNDAMENTAÇÃO TEÓRICA}

As plantas de mangue possuem um grande potencial para uso na descoberta de compostos bioativos, devido a seus fatores abióticos e condições ambientais severas nas quais essas plantas sobrevivem. (RODRIGUES et al., 2015). Além das marés, a quantidade de água doce que o manguezal recebe também é fundamental para o desenvolvimento e manutenção deste ambiente. Nessa ambiência há uma diluição da salinidade que determina a instalação e sobrevivência das espécies vegetais do manguezal, a distribuição dos organismos aquáticos e fatores ambientais como, por exemplo, temperatura, oxigênio dissolvido, pH, nutrientes e metais (ALVES, 2001).

A temperatura do ar e da água também é fundamental para o desenvolvimento dos manguezais, que preferem os ambientes mais quentes da região tropical com temperaturas médias anuais acima dos $20^{\circ} \mathrm{C}$ (MAJOR, 2002).

Essas espécies conseguem produzir carboidratos, polifenóis e outros compostos químicos que atuam na defesa dessas plantas e promovem seu desenvolvimento efetivo em ambientes agressivos (RODRIGUES et al., 2015).

As espécies de mangue são plantas halófitas ou pelo menos tolerantes à salinidade (VANNUCCI, 1999). A maioria das espécies também cresce em água doce, mas o crescimento é estimulado por condições salinas (BALL, 1988), apresentando crescimento máximo em baixas concentrações de sal (BALL, 1998). Além disso, nessas condições elas dominam por exclusão competitiva de outras espécies que não toleram tais condições (VANNUCCI, 2001). Para viver em ambientes salinos ou fisiologicamente secos, os mangues possuem adaptações xerófitas, incluindo a presença de tecidos de armazenamento de água, estômatos em depressão e aerênquima (THONLINSON, 1986). Algumas espécies possuem glândulas secretoras de sal, que conferem uma maior tolerância e flexibilidade em lidar com as flutuações no fluxo de sal para a parte aérea (YE et al., 2005). Estas espécies apresentam características fisiológicas e adaptações especiais ao local que se encontram, permitindo dessa forma, longos períodos de exposição em água, regime diário das marés, alta salinidade, baixo teor de oxigênio e substratos inconsolidados (REVATHI et al., 2013; ARAÚJO, 2015).

Segundo a Organização Mundial da Saúde (OMS), planta medicinal é considerada todo e qualquer vegetal que possui, em um ou mais órgãos, substâncias que podem ser utilizadas para fins terapêuticos ou que sejam precursores de fármacos semissintéticos. As plantas medicinais estão distribuídas de forma universal em diversos lugares, inclusive no manguezal.

No litoral brasileiro, os gêneros mais abundantes são Avicennia (Avicenniaceae), Laguncularia (Combretaceae) e Rhizophora (Rhizophoraceae), e representantes do gênero 
Conocarpus (Combretaceae) (SILVA, 2004).

Algumas espécies pertencentes ao mangue, como o mangue branco (Laguncularia racemosa) e o mangue vermelho (Rhizophora mangle) apresentam propriedades capazes de sintetizar substâncias (sais, ácidos orgânicos, carboidratos, alcaloides, flavonoides e taninos) utilizados na área médica, agronômica e cosmética (SEBASTIANES, 2010).

Plantas que possuem substâncias com propriedades medicinais de alto interesse farmacológico, demonstram ser uma excelente fonte para produção de medicamentos e seus derivados (SILVA, 2004).

Levando em consideração a grande biodiversidade do manguezal, a importância do seu estudo e a necessidade da busca sobre suas propriedades fitoquímicas para a reafirmação do uso pelas comunidades, o objetivo do presente estudo foi identificar as propriedades medicinais oriundas do mangue do Estado de Pernambuco e conhecer as características e aspectos que fazem com que estabeleçam a cura e o tratamento de diversas doenças.

\section{METODOLOGIA}

A pesquisa é de natureza qualitativa, constituída por pesquisas em artigos científicos, teses e dissertações nos bancos de dados Google Acadêmico e Scielo, entre os anos 2008 a 2019, com o objetivo de reunir dados sobre as propriedades medicinais de plantas do mangue do Estado de Pernambuco. Como critérios de inclusão foram admitidos artigos que apresentaram os usos populares da Avicennia (Avicenniaceae), Laguncularia (Combretaceae), Rhizophora (Rhizophoraceae), e Conocarpus (Combretaceae), bem como os artigos que apresentaram investigações fitoquímicas e propriedades biológicas das referidas plantas. Como critérios de exclusão, não foram adotados para a pesquisa, artigos publicados em datas fora da margem dos anos escolhidos para estudo.

Foram selecionados 25 artigos com base nos critérios de inclusão adotados e os resultados foram agrupados segundo a atividade biológica relatada para cada espécie e a sua respectiva referência bibliográfica.

\section{RESULTADOS E DISCUSSÃO}

De acordo com a pesquisa realizada entre os anos de 2008 a 2019, dos 25 artigos selecionados, foi possível confirmar a publicação de relatos sobre o uso medicinal da Avicennia (Avicenniaceae), Laguncularia (Combretaceae), Rhizophora (Rhizophoraceae) e Conocarpus (Combretaceae) para as para os mais diversos fins medicinais, citados a seguir na tabela 1. 
Tabela 1: Plantas medicinais do mangue pernambucano e suas características.

\begin{tabular}{|c|c|c|c|c|}
\hline $\begin{array}{l}\text { NOME } \\
\text { POPULAR }\end{array}$ & $\begin{array}{l}\text { NOME } \\
\text { CIENTÍFICO }\end{array}$ & FAMÍLIA & $\begin{array}{l}\text { UTILIZAÇÃO } \\
\text { POPULAR }\end{array}$ & AUTOR \\
\hline $\begin{array}{l}\text { Mangue- } \\
\text { Preto }\end{array}$ & Avicennia sp & Avicenniaceae & $\begin{array}{l}\text { Úlceras pépticas, } \\
\text { diarreia } \\
\text { hemorroidas, dor } \\
\text { reumática. }\end{array}$ & $\begin{array}{l}\text { SUMITHRA et al. (2011); } \\
\text { THIRUNAVUKKARASU et al. } \\
\text { (2011). }\end{array}$ \\
\hline $\begin{array}{l}\text { Mangue- } \\
\text { Branco }\end{array}$ & $\begin{array}{l}\text { Laguncularia } \\
\text { racemosa L. }\end{array}$ & Combretaceae & Antimicrobiana. & SILVA et. al., (2011) \\
\hline $\begin{array}{l}\text { Mangue- } \\
\text { Vermelho }\end{array}$ & $\begin{array}{l}\text { Rhizophora } \\
\text { mangle }\end{array}$ & Rhizophoraceae & $\begin{array}{l}\text { Anti-inflamatória } \\
\text { antioxidante, } \\
\text { cicatrizante, contra } \\
\text { úlcera } \\
\text { hipoglicemia. }\end{array}$ & $\begin{array}{l}\text { MARRERO et al., (2006); } \\
\text { BERENGUER et al., (2006), } \\
\text { FERNANDEZ et al., (2002); } \\
\text { PERERA etal.,(2001) ; } \\
\text { ALARCON-AGUILARA et al., } \\
\text { 1998). }\end{array}$ \\
\hline $\begin{array}{l}\text { Mangue-de- } \\
\text { Botão }\end{array}$ & $\begin{array}{l}\text { Conocarpus } \\
\text { erectus L. }\end{array}$ & Combretaceae & $\begin{array}{l}\text { Anemia, febre, } \\
\text { diabetes, diarreia, } \\
\text { hemorragia, } \\
\text { conjuntivite, dor de } \\
\text { cabeça. }\end{array}$ & $\begin{array}{l}\text { ABDEL-HAMEED et al., } \\
(2013) \text {. }\end{array}$ \\
\hline
\end{tabular}

Fonte: Própria (2019)

Mangue-Preto (Avicennia schaueriana)

O mangue-preto apresenta estruturas de respiração chamadas de pneumatóforos, que são raízes que crescem num sistema radicular e que depois sobem, ficando acima do solo, auxiliando assim a respiração da árvore (OLIVEIRA, 2005).

O gênero Avicennia é o único que ocorre em todo o mundo. Junto com Rizophora, eles formam uma dominância em relação as comunidades de florestas de mangue (THATOI et al., 2016).

Há relatos sobre a importância de diversas partes de espécies com uso etnomedicinal, onde o chá preparado a partir da casca é utilizado para tratar uma variedade de distúrbios digestivos como úlceras pépticas, diarreia incluindo hemorróidas, 
dor reumática e assim por diante. (SUMITHRA et al. 2011; THIRUNAVUKKARASU et al. 2011).

As espécies de Avicennia se distribuem por todo o Brasil e se distinguem pelo desenvolvimento pronunciado de raízes salientes, as quais são denominadas de pneumatóforos, pode alcançar alturas de $20 \mathrm{~cm}$ ou mais (RODRÍGUEZ-ZÚÑIGA et al., 2015).

\section{Mangue Branco (Laguncularia racemosa L.)}

Laguncularia racemosa L. Gaertn. f. (Combretaceae) é uma espécie arbórea halófita, que se desenvolve sob influência da inundação pelas marés, nos solos instáveis, salinos e anóxicos característicos do ecossistema manguezal (OLIVEIRA, 2005).

De acordo com Silva et al., (2011), fungos endofíticos isolados das folhas de $L$. racemosa produzem metabólitos secundários com atividade antimicrobiana. $\mathrm{O}$ isolamento e caracterização dessas substâncias podem levar à descoberta de novos compostos de interesse farmacêutico, especialmente no tratamento de infecções causadas por bactérias. Além disso, essas plantas apresentam uma série de defesas contra a herbivoria, destacando-se a síntese de metabólitos secundários. Dentre esses, temos os polifenóis, constituídos principalmente por taninos condensados e outros fenóis com atividade adstringente (KANDIL et al., 2004).

\section{Mangue Vermelho (Rhizophora mangle)}

As espécies vegetais do gênero Rhizophora são conhecidas pelas várias propriedades medicinais que possuem. R. mangle é conhecida popularmente como "Mangue-Vermelho", "Mangue Garobeira", "Mangue de Espeto", "Mangue de Pendão", "Mangue Sapateiro", e "Mangue Verdadeiro", principalmente na região nordeste do Brasil (CARDOSO; SALARO; VILEGAS, 2015).

Rhizophora mangle L., é uma espécie endêmica da vegetação de manguezal, que faz parte da família Rhizophoraceae. Essa vegetação possui caráter arbóreo com folhas simples e adaptações fisiológicas notáveis frente aos substratos anaeróbicos típicos do manguezal, os rizóforos (FERREIRA, et al., 2011).

O mangue-vermelho é rico em substâncias fenólicas, como taninos, que são largamente utilizadas na produção de corantes. Algumas propriedades farmacológicas de Rhizophora mangle L. têm sido determinadas, como as atividades anti-inflamatória (MARRERO et al., 2006), antioxidante (BERENGUER et al., 2006), cicatrizante (FERNANDEZ et al., 2002); contra úlcera (PERERA et al., 2001; BERENGUER et al., 2006) e hipoglicêmica (ALARCONAGUILARA et al., 1998). 
Mangue-de-botão (Conocarpus erectus L.)

A espécie Conocarpus erectus L. é popularmente conhecida por nome popular de "mangue botão" que pertence à família Combretaceae, podendo ser encontrada nos manguezais em regiões tropicais e subtropicais em todo o mundo (VIEIRA, 2017).

As folhas, caules, frutos e flores possuem em sua composição propriedades antioxidantes, anticancerígenos e antimicrobianos. Na medicina popular é utilizada na prevenção de anemia, diabetes, conjuntivite, dor de cabeça, diarreia, febre e, hemorragia (ABDEL-HAMEED et al., 2013).

De acordo com trabalho de Shohayeb et al. (2013), C. erectus é usado como um remédio para vários doenças como anemia, catarro, orquite, úlceras na pele e sífilis. Em análise de extratos de $C$. erectus foram detectadas capacidades antioxidantes e anticancerígenas (NAHLA, 2010). A crescente incidência de resistência de agentes patogênicos e bactérias a antibióticos enfatiza a necessidade de plantas para sua potencial atividade antimicrobiana (SHOHAYEB et al., 2013).

\section{CONCLUSÃO}

Por meio do presente estudo, foi possível constatar a importância e versatilidade quanto ao uso das plantas medicinais oriundas do mangue Pernambucano. Observou-se que as espécies estudadas têm grande potencial de uso, já que são fontes de moléculas bioativas de grande interesse e relevância para uso farmacológico, tais como sais, ácidos orgânicos, carboidratos, alcaloides, flavonoides, taninos, dentre outras, que podem ser extraídas e utilizadas na área médica, cosmética e agronômica.

Além disso, pode-se destacar o variado e recorrente emprego dessas plantas na medicina popular, o que ressalta a necessidade da ocorrência de mais estudos na referida área, visando tanto a ampliação do conhecimento a respeito de suas características e potencialidades quanto a segurança e eficácia de uso por parte da população.

\section{REFERÊNCIAS}

AlbuQUerQue, A.; FREITAS, E.; MOURA-FÉ, M.M.; BARbOSA, W. A PROTEÇÃo DOS ECOSSISTEMAS DE MANGUEZAL PELA LEGISLAÇÃO AMBIENTAL BRASILEIRA. GEOgraphia - Ano. 17 - N³3 - 2015.

ALMEIDA, Z.S; FÔNSECA, V.G. 1999. Análise quali-quantitativa da meiofauna na região de Itapissuma - PE. Pesq. Foco. São Luiz, 7 (9): 115-137. 
ANUNCIADA, CRISTIANE; GOMES, ANDRÉ; SANTOS, PAULO JORGE PARREIRA; ALVES, TATIANA NUNES CAVALCANTI; FILHO, JOSÉ SOUTO ROSA; SANTOS, LÍLIA PEREIRA SOUZA. VARIAÇÃO TEMPORAL DA MEIOFAUNA EM ÁREA DE MANGUEZAL EM ITAMARACÁ - PERNAMBUCO. Atlântica, Rio Grande, 24(2): 8996, 2002.

ARAÚJO, J. G. Desenvolvimento de creme de Rhizophora mangle L.: Avaliação do potencial cicatrizante em feridas cutâneas. Universidade Federal de Pernambuco. Dissertação de Mestrado. Programa de Pós-Graduação em Ciências da Saúde, Recife, 2015.

BANDEIRA, A. R. G. Estudo fitoquímico e atividade biológica de Conocarpus erectus L. (Mangue botão). Universidade Federal de Pernambuco. Dissertação de Mestrado. Centro de Ciências Biológicas, Departamento de antibióticos, Pós-Graduação em biotecnologia de produtos bioativos. Recife, 2003.

BARBOSA, F. G. Estrutura e análise espaço temporal da vegetação do manguezal do Pina, Recife - PE: subsídios para manejo, monitoramento e conservação. Universidade Federal de Pernambuco - CFCH. Dissertação de Mestrado. Programa de Pós-Graduação em Geografia. Recife, 2010.

BERENGUER, B.; SÁNCHEZ, L. M.; QUÍLEZ, A.; LÓPEZ-BARREIRO, M.; HARO, BRANCO, L.H.Z.; MOURA, A.N.; SILVA, A.C.; OLIVEIRA, M.C.B. BIODIVERSIDADE E CONSIDERAÇÕES BIOGEOGRÁFICAS DAS CYANOBACTERIA DE UMA ÁREA DE MANGUEZAL DO ESTADO DE PERNAMBUCO, BRASIL. Acta bot. bras. 17(4): 585-596. 2003.

CARDOSO, C. R. P.; SALARO, M. C. F.; VILEGAS, W. Controle de qualidade preliminar de Rhizophora mangle, planta do litoral brasileiro. III Simpósio de Tecnologia Sucroenergética e de Biocombustíveis. Ciência \& Tecnologia: Fatec-JB, Jaboticabal, v. 7, 2015. Suplemento.

CARNEIRO, M.A.B; FARRAPEIRA, C.M.R; SILVA, K.M.E. O manguezal na visão etnoecológica dos pescadores artesanais do Canal de Santa Cruz, Itapissuma, Pernambuco, Brasil.

EL-SAYED S. ABDEL-HAMEED, SALIH A. BAZAID and ABDEL NASSER A. SABRA.2013. Protective Effect of Conocarpus erectus .Extracts on CC 14-Induced Chronic Liver Injury in Mice. ISSN 1992-0075. DOI: 10.5829/idosi.gjp.2013.7.1.7188. Global Journal of Pharmacology 7 (1): 52-60, 2013.

FERREIRA, F.S.; SANTOS, S.C.; BARROS, T.F.; ROSSI-ALVA, J.C.; FERNANDEZ, L.G. Atividade antibacteriana in vitro de extratos de Rhizophora mangle L. Rev. Bras. Pl. Med., Botucatu, v.13, n.3, p.305-310, 2011.

GOMES, C.A.A.P.; SANTOS, J.P.; ALVES,T.N.C.; FILHO, J.S.R.; SANTOS. L. P.S. VARIAÇÃO TEMPORAL DA MEIOFAUNA EM ÁREA DE MANGUEZAL EM ITAMARACÁ - PERNAMBUCO. Atlântica, Rio Grande, 24(2): 89-96, 2002.

Lima, D.A. ESTUdOS FITOGEOGRÁFICOS DE PERNAMBUCO. Anais da Academia Pernambucana de Ciência Agronômica. 
LIMA, D.ANDRADE. ESTUDOS FITOGEOGRÁFICOS DE PERNAMBUCO. Anais da Academia Pernambucana de Ciência Agronômica, Recife, vol. 4, p.243-274, 2007.

MACEDO \& T LIMA (eds). Gerenciamento participativo de estuários e manguezais. Recife, Cap. 3: 89-102.

MARRERO, E.; SÁNCHEZ, J.; ARMAS, E.; ESCOBAR, A.; MELCHOR, G.; ABAD, M. J.; BERMEJO, P.; VILLAR, A. M.; ALCARAZ, M. J. COX-2 and sPLA2 inhibitory activity of aqueous extract and polyphenols of Rhizophora mangle (red mangrove). Fitoterapia, v.77, n. 4, p.313-5, 2006.

MARTINS, P.T.A; COUTO, E.C. G; DELABIE, J.H.C. Fitossociologia e estrutura vegetal do Manguezal do rio Cururupe (Ilhéus, Bahia, Brasil). Revista da Gestão Costeira Integrada 11(2):163-169 (2011).

MARTINS, Patrick Thomaz de Aquino. Análise das intervenções antrópicas no manguezal do rio Cachoeira, Ilhéus, Bahia. 2008. 85 f. Dissertação (Mestrado em Geografia) Universidade Federal de Sergipe, São Cristóvão, 2008.

MATTOS, P. P.; KONIG, A.; FREIRE, F. A. M.; ALOUFA, M. A. I. Etnoconhecimento e percepção dos povos pesqueiros da Reserva Ponta do Tubarão acerca do ecossistema manguezal. Revista Brasileira de Biociências. ISSN 1980-4849 (on-line) / 1679-2343 (print). Porto Alegre, v. 10, n. 4, p. 481-489, out./dez. 2012.

NAHLA, A. A. A trime thoxyellagic acid glucuronide from Conocarpus erectus leaves: Isolation, characterization and assay of antioxidant capacity. Pharm Biol, 48: 328- 332, 2010.

O.; GÁLVEZ, J.; MARTÍN, M. J. Protective and antioxidant effects of Rhizophora mangle L. against NSAID-induced gastric ulcers. Journal of Ethnopharmacology, v.103, n.2, p.194200, 2006.

OLIVEIRA, V. F. Influência do estresse hídrico e salino na germinação de propágulos de Avicennia schaueriana Stapf e Leechman ex Moldenke e Laguncularia racemosa (L.) Gaertn. f. Rio de Janeiro. Dissertação (mestrado) - Instituto de Pesquisas Jardim Botânico do Rio de Janeiro/Escola Nacional de Botânica Tropical, 2005.

PORTUGAL, Ana Margarida Marques; SCHAEFFER-NOVELLI, Yara. Manguezais de Guaratiba frente à perspectiva de elevação do nível médio relativo do mar, Baía de Sepetiba, Estado do Rio de Janeiro - Brasil. 2002.Universidade de São Paulo, São Paulo, BSP, 2002.

REVATHI, P., SENTHINATH, T. J., THIRUMALAIKOLUNDUSUBRAMANIAN, P.; PRABHU, N. Medicinal Properties of Mangrove Plants - an overview. International Journal of Bioassays, v. 2, n.12, p. 1596-1600, 2013.

RODRIGUES, C. F. B.; GAETA, H. H.; BELCHOR, M. N.; FERREIRA, M. J. P.; PINHO, M. V. T.; TOYAMA, D. O.; TOYAMA, M. H. Evaluation of Potential Thrombin Inhibitors from the White Mangrove (Laguncularia racemosa (L.) C.F. Gaertn.) Mar. 
Drugs 2015, 13, 4505-4519; doi:10.3390/md13074505. Marine drugs ISSN 1660-3397 www.mdpi.com/journal/marinedrugs

RODRÍGUEZ-ZÚNIGA, M. T.; Troche-Souza, C., Vázquez-Lule, A. D., Márquez-Mendoza, J. D., Vázquez-Balderas, B., Valderrama-Landeros, L., Cerdeira-Estrada, S. Comisión Nacional para el Conocimiento y Uso de la Biodiversidad. México DF, 2015 http://www.biodiversidad.gob.mx/ecosistemas/manglares2013/pdf/folleto_manglares_web.pd f> acessado em 10 set. 2016.

SANTOS, P.J.P, GOMES, C.A.A; ALMEIDA, Z.S.; FÔNSECA; V.G \& SANTOS, LPS. 2000. Diversidade de Copepoda Harpacticoida em área de manguezal do Canal de Santa de Cruz, PE, Brasil. Publ. Acad. Sci. São Paulo, 109 (2): 319-326.

SCHAEFFER-NOVELLI, Y.; CINTRÓN, G. M. 1986. Guia para estudo de áreas de manguezal: estrutura, função e flora. [S.1.]: Caribbean Ecological Research. 186 p.

SEBASTIANES, F. L. S. Diversidade genética e potencial biotecnológico de fungos endofíticos de manguezais do estado de São Paulo. 2010. 150f. Tese de doutorado. Universidade de São Paulo, Escola Superior de Agricultura Luiz de Queiroz, Piracicaba, 2010.

Seixas, J..A.S.; Fernandes, M.E.B.; Silva, E.S. Análise estrutural da vegetação arbórea dos mangues no Furo Grande, Bragança, Pará. Bol. Mus. Para. Emilio Goeldi Cienc. Nat. v.1 n.3 Belém dez. 2006.

Sérgio, C; Leite, E.; Pitteri, H.; Martuscelli, J.; Machado, P. CARACTERIZAÇÃO MORFOFISIOLÓGICA DO MANGUEZAL DE CANANÉIA - SP.Environmental and Health World Congress.July 16 - 19, 2006, Santos, BRAZIL.

SHOHAYEB, M.; ABDEL-HAMEED E.; BAZAID, S. ANTIMICROBIAL ACTIVITY OF TANNINS AND EXTRACTS OF DIFFERENT PARTS OF CONOCARPUS ERECTUS L. Available Online through www.ijpbs.com (or) www.ijpbsonline.com. International Journal of Pharmacy and Biological Sciences (e-ISSN: 2230-7605). IJPBS, Volume 3. Issue 2 |APRJUN |2013|544-553.

SILVA, E.V; SOUZA, M.M.A. Principais formas de uso e ocupação dos manguezais do Estado do Ceará. Universidade Federal do Ceará, Fortaleza, CE, Brasil.

SILVA, J. M.; MARTINS, M.B.G.; CAVALHEIRO, A.J. Caracterização anatômica e perfil químico da lâmina foliar de Laguncularia racemosa (L.) Gaertn, de manguezais impactados e não impactados do litoral de São Paulo. Fundação zoobotânica-RS v. 65, n. 2 (2010).

Silva, J.M.; Martins, M.B.G.; Cavalheiro, A.J. Caracterização anatômica e perfis químicos de folhas de Avicennia schaueriana Stapf. \& Leech. ex Moldenke e Rhizophora mangle L. de manguezais impactados e não impactados do litoral paulista.doi: 10.5007/21784574.2010v39p14.

SILVA, M. R. O. Detecção da atividade antifúngica de extratos de plantas do manguezal de Vila Velha, Itamaracá - PE. Universidade Federal de Pernambuco. Dissertação de Mestrado. Pós-Graduação em Biologia de Fungos. Recife, 2004.

SILVA, M. R. O.; ALMEIDA, A. C.; ARRUDA, F. V. F.; GUSMÃO, N. Endophytic fungi 
from brazilian mangrove plant Laguncularia racemosa (L.) Gaertn. (Combretaceae): their antimicrobial potential. Science against microbial pathogens: communicating current research and technological advances A. Méndez-Vilas (Ed.). 2011.

SOARES, S. R. F. Cultivo de mudas de Laguncularia racemosa (L.) C. F. Gaertn com uso de águas hipersalinas e diferentes substratos. Tese de Doutorado. Universidade Federal Rural do Semi-Árido. Programa de pós-graduação em Manejo de Solo e água. Mossoró-RN, 2017.

SUMITHRA M, ANBU J, NITHYA S, RAVICHANDIRAN V. 2011. Anticancer activity of methanolic leaves extract of Avicennia officinalis on ehrlich ascitis carcinoma cell lines in rodents. International Journal of PharmTech Research CODEN (USA): IJPRIF ISSN: 09744304 Vol.3, No.3,pp 1290-1292, July-Sept 2011.

TEIXEIRA, K. C. S. Propagação de plantas de mangue visando a recuperação de áreas degradadas. Universidade Federal de Sergipe. Dissertação de Merstrado. Núcleo de PósGraduação em Desenvolvimento e Meio Ambiente, Pró-Reitoria de Pós-Graduação e Pesquisa. Sergipe, 2008.

THATOI, H.; SAMANTARAYB, D.; DAS. S. K. The genus Avicennia, a pioneer group of dominant mangrove plant species with potential medicinal values: a review. FRONTIERS IN LIFE SCIENCE, $2016 \quad$ VOL. $\quad 9, \quad$ NO. $\quad 4, \quad 267-291$ http://dx.doi.org/10.1080/21553769.2016.1235619.

THIRUNAYUKKARASU P, RAMANATHAN T, RAMKUMAR L, SHANMUGAPRIYA R, RENUGADEVI G. 2011. The antioxidant and free radical scavenging effect of Avicennia officinalis. Journal of Medicinal Plants Research Vol. 5(19), pp. 4754-4758, 23 September, 2011 Available online at http://www.academicjournals.org/JMPR ISSN 1996-0875 (C2011 Academic Journals

VIEIRA, V. R. ATIVIDADE CITOPROTETORA E CICATRIZANTE DA ESPÉCIE Conocarpus erectus L EM LESÕES GÁSTRICAS INDUZIDAS EM RATOS WISTAR ADULTOS. UNIVERSIDADE FEDERAL DO PARÁ INSTITUTO DE CIÊNCIAS DA SAÚDE PROGRAMA DE PÓS-GRADUAÇÃO EM QUIMICA MEDICINAL E MODELAGEM MOLECULAR. Dissertação de Mestrado, Belém-PA, 2017. 